Daniel Ferreira Fagundes 1,2

(D) https://orcid. org/0000-0002-5875-9904

Marcos Túlio Costa

(- https://orcid.org/0000-0003-4712-2649

Bárbara Bispo da Silva Alves Ohttps://orid. org/0000-0002-7801-2621

Maria Madalena Soares Benício Ohttps://orcid. org/0000-0002-7517-2726

Lanna Pinheiro Vieira

O https://orcid.org/0000-0002-2960-2473

Lara S. F. Carneiro 3,4,5

Ohttps://orcid.org/0000-0002-4385-5290

Osvaldo José Moreira Nascimento² Ohttps://orid.org/0000-0003-3516-485X

Renato Sobral Monteiro-Junior 1,2,6 Ohttps://orcid.org/0000-0002-8472-262X

\section{Prevalence of dementia in long-term care institutions: a meta-analysis}

Prevalência de demência em instituições de longa permanência: uma metanálise

DOI: $10.1590 / 0047-2085000000298$

\section{ABSTRACT}

Objective: This study comprises a systematic review and meta-analysis that aimed to estimate the prevalence of dementia in long-term care institutions (LTCIs). Methods: We used the Preferred Reporting Items for Systematic reviews and Meta-Analyses (PRISMA). Original transversal and longitudinal articles published until July 2020 were eligible in this review. Databases PubMed/MedLine, Web of Science, Scopus and ScienceDirect were searched. Overall prevalence and confidence intervals were estimated. Heterogeneity was calculated according to the index of heterogeneity (12). Results: One hundred seventy-five studies were found in all databases and 19 studies were meta-analyses, resulting in an overall prevalence of 53\% (Cl 46-59\%; p < 0.01) of demented older adults living in LTCls. Conclusion: Prevalence of dementia is higher in older adults living in LTCls than those living in general communities. This data shows a worrying reality that needs to be changed. There is a need for a better understanding of the elements that cause this increase in dementia in LTCFs to direct actions to improve the quality of life and health of institutionalized elderly.

\section{KEYWORDS}

Dementia, prevalence, epidemiology, long-term care institutions, nursing homes, health facilities, institutionalization.

\section{RESUMO}

Objetivo: Esta revisão sistemática e metanálise objetiva estimar a prevalência de demência em instituições de longa permanência para idosos (ILPIs). Métodos: Utilizou-se o Preferred Reporting Items for Systematic Reviews and Meta-Analyses (PRISMA). Artigos originais transversais e longitudinais publicados até julho de 2020 foram elegíveis para esta revisão. As buscas foram conduzidas por meio das bases de dados do PubMed/MedLine, Web of Science, Scopus e Science Direct. A prevalência geral e o intervalo de confiança foram estimados. A heterogeneidade foi calculada de acordo com o índice de heterogeneidade $\left({ }^{2}\right)$. Resultados: Cento e setenta e cinco estudos foram encontrados em todas as bases de dados e 19 estudos foram analisados, resultando em uma prevalência geral de idosos com demência de 53\% (IC 46-59\%; p < 0,01) que habitam em ILPIs. Conclusão: A prevalência de demência é maior em idosos moradores de ILPIs que em idosos da população geral. Tal dado mostra uma realidade preocupante e que precisa ser modificada. Há necessidade de melhor entendimento dos elementos que causam esse aumento de demência nas ILPIs para direcionar ações para melhorar a qualidade de vida e a saúde dos idosos institucionalizados.

\section{PALAVRAS-CHAVE}

Demência, prevalência, epidemiologia, instituições de longa permanência, lar de idosos, instituições de saúde, institucionalização.
Received in: Dec/18/2019 Approved in: Sep/2/2020

1 Universidade Estadual de Montes Claros, Centro de Ciências Biológicas e da Saúde, Montes Claros, MG, Brasil.

2 Universidade Federal Fluminense, Programa de Pós-Graduação em Neurologia, Niterói, RJ, Brasil.

3 Instituto Superior de Ciências Educativas do Douro, Penafiel, Portugal.

4 Instituto Universitário da Maia, Maia, Portugal.

5 Centro de Investigação em Saúde, Desporto e Desenvolvimento Humano, Portugal.

6 Aroldo Tourinho Hospital, Instituto de Neurociência do Exercício, Montes Claros, MG, Brasil.

Address for correspondence: Renato Sobral Monteiro-Junior. Universidade Estadual de Montes Claros. Av. Doutor Rui Braga, s/n, Vila Mauricéía - $39401-089$ Montes Claros, MG, Brasil. Telefone +55 (38) 3229-8289. E-mail: monteirojuniorms@gmail.com 


\section{INTRODUCTION}

Dementia is a syndrome characterized by poor cognition (e.g., impaired memory, language, executive function, attention and visuospatial perception) and functional decline? Compared to European and North American countries, Latin America $(L A)$ is experiencing this unprecedented demographic change at a significantly faster rate. Due to demographic and health transitions, the number of people with dementia in Latin America will increase from 7.8 million in 2013 to over 27 million by 2050. Possible causes of this increase in dementia in developing countries are limited access to primary care, low education and a high incidence of curable diseases such as systemic arterial hypertension and syphilis. Hence the need for an increasing understanding of dementia in the developing world ${ }^{2}$. In Brazil, the prevalence of dementia is $7.1 \%$ in people aged 65 and over $^{3}$. This condition affects about 50 million people worldwide ${ }^{4}$ and is a major cause of death and disability among older adults ${ }^{5}$.

There are different types of dementia, such as Alzheimer's disease (AD), frontotemporal dementia, Lewy body dementia, vascular dementia and mixed dementia, although AD prevails $(60 \%-80 \%)^{6,7}$. As dementia causes functional disabilities, patients families are not always able to provide these individuals suitable care, thus resulting in their institutionalization in long-term care institutions (LTCls). Other reasons that also lead to the institutionalization of the elderly are the presence of cognitive impairment, neurodegenerative diseases, neuropsychological disorders, and caregiver burden ${ }^{8,9}$.

People living in LTCls have few general stimulation, physical activities and cognitive challenges, and poor social interaction, which contribute to the increased risk of cognitive decline and dementia ${ }^{10,11}$. However, the prevalence of dementia in LTCls is unknown. Determining the prevalence of dementia is the initial step to evaluate the health expenditure for the elderly population, while also an important tool to improve health care for this population ${ }^{12}$. With this data, long-term institutions can improve the availability of nursing care services and other health professionals, organizing special teams with knowledge on dementia to support family members and the elderly who reside in these institutions ${ }^{13}$. Thus, understanding the prevalence of dementia in the elderly in $\mathrm{LTCl}$ is crucial for institutions. Therefore, the aim of this study was to conduct a systematic review of the literature and estimate the prevalence of dementia in LTCls through a meta-analysis.

\section{METHODS}

This study used the Preferred Reporting Items for Systematic Reviews and Meta-Analyses (PRISMA) ${ }^{14}$.

\section{Eligibility criteria}

This review encompassed original articles published in peer-reviewed and indexed journals until July 2020, in any language, which analysed the prevalence of dementia in LTCls or those with quantitative data that allowed for the calculation of the proportion of people with dementia.

\section{Inclusion criteria}

This systematic review and meta-analysis included original transversal and longitudinal articles involving elderly people from long-term institutions. The articles must present the instruments and criteria used for the diagnosis of dementia or the strategies used to calculate the prevalence of dementia in LTCls, such as MEEM, CDR, MoCA, DSM criteria, and the analysis of medical records.

\section{Information sources}

Four databases were used to retrieve studies: PubMed/ MedLine, Web of Science, Scopus, and ScienceDirect. The following key-terms were searched in the study titles and combined in the search strategy: dementia, prevalence, epidemiology, long-term care, nursing home, institution and institutionalized. Booleans OR/AND were used as follow: dementia[Title]) AND prevalence[Title] OR epidemiology[Title] AND long-term care[Title] OR nursing home[Title] OR institution[Title] OR institutionalized[Title]. The database search using this strategy was carried out on August 2, 2020.

\section{Exclusion criteria}

Studies with unclear sample size or those which did not allow to calculate proportions of demented patients were excluded. No observational studies or those which investigated specific populations (e.g., people with Lewy body dementia, leprosy, Parkinson's disease) were also excluded.

\section{Study selection}

All the studies were grouped into a spreadsheet. Duplicated studies retrieved from databases were marked to be excluded. Then, titles and abstracts were read to identify coherence with the scope of the review. Lastly, full texts were carefully read to screen potential outcomes to be extracted. Two independent reviewers conducted the data selection and extraction. Any doubts were discussed between the two reviewers. In the absence of a consensus, a third reviewer was consulted. Potentially missing articles in the reference lists of the selected articles were analyzed, however, most articles in the reference lists had already been selected by the search strategy. Other articles, not selected by the electronic search did not present inclusion criteria in the review. 


\section{Data collection process}

The number of institutionalized older adults as the demented patients in each LTCl was extracted from the selected studies. Absolute and relative frequencies were recorded when available.

\section{Synthesis of results}

The overall prevalence and confidence intervals were estimated through Freeman-Tukey analysis. Heterogeneity was calculated according to the index of heterogeneity $\left(I^{2}\right)$ proposed by Higgins ${ }^{15}$. Stata 11.0 was used to perform these analyses.

\section{Study quality assessment}

To analyze the quality of the studies, the Checklist for Measuring Quality proposed by Downs and Black ${ }^{16}$ was used. Items related to experimental studies were excluded. Thus, 17 items were evaluated. Studies with more than 12 points can be considered of greater methodological rigor.

\section{Risk of bias}

Publication bias was analyzed according to the visual inspection of the Funnel Plot (FP). This analysis is based on a chart where each study is positioned due to its precision (standard error) and effect size ${ }^{35}$. Robust studies showing high effect size tend to be displayed at the top of the funnel, while those with small effect size or small sample sizes are displayed at the bottom of the chart ${ }^{36}$.

\section{RESULTS}

\section{Included and analyzed studies}

One hundred seventy-five studies were found in all databases. Ninety-nine duplicated studies were removed. Sixty-eight articles were read except eight of them, which were not found in full text even after attempting to contact the corresponding author by e-mail. Forty-nine studies did not show complete data on the prevalence or have not data to calculate it. Hence, 19 studies were analyzed resulting in $53 \%$ overall prevalence $(\mathrm{Cl} 46-59 \% ; \mathrm{p}<0.01)$ of demented older adults living in LTCls. From all analyzed studies, fourteen were performed in European countries, whereas two in Asia, two in America, and one in Africa and Eurasia. Norway and Mexico showed the highest (84\%) and the lowest (11\%) prevalence of dementia, respectively. Details of the screening procedure and main results are shown in figures 1-3 and tables 1 and 2 . Heterogeneity among studies was high (98.76\%; $p<0,01$ ), thus a random effect model was used in the main analysis.

Table 1. Level of evidence (Downs and Black scale)

\begin{tabular}{|c|c|c|c|c|c|}
\hline Author, Year & Reporting & External validity & Bias & Confoundin & Score \\
\hline$X u^{17}, 2017$ & 6 & 2 & 3 & 4 & 15 \\
\hline Helvik ${ }^{13}, 2015$ & 7 & 2 & 3 & 3 & 15 \\
\hline Helvik ${ }^{13}, 2015$ & 7 & 2 & 3 & 3 & 15 \\
\hline Ouanes $^{18}, 2014$ & 6 & 2 & 3 & 4 & 15 \\
\hline Zwakhalen ${ }^{19}, 2009$ & 4 & 2 & 3 & 3 & 12 \\
\hline Jakob $^{20}, 2002$ & 9 & 0 & 3 & 2 & 14 \\
\hline Burton $^{21}, 2001$ & 9 & 2 & 3 & 2 & 16 \\
\hline Adolfsson ${ }^{22}, 1981$ & 7 & 1 & 2 & 1 & 11 \\
\hline Auer $^{23}, 2018$ & 9 & 2 & 2 & 4 & 17 \\
\hline Hutsteiner ${ }^{24}, 2013$ & 7 & 2 & 3 & 2 & 14 \\
\hline Reuther ${ }^{25}, 2013$ & 8 & 2 & 2 & 3 & 15 \\
\hline Guo $^{26}, 2012$ & 6 & 2 & 3 & 2 & 13 \\
\hline Amuk $^{27}, 2009$ & 7 & 2 & 3 & 1 & 13 \\
\hline Wancata ${ }^{28}, 2004$ & 7 & 2 & 3 & 3 & 15 \\
\hline Alvarado-Esquivel29, 2004 & 7 & 2 & 2 & 1 & 12 \\
\hline Donnelly ${ }^{30}, 1989$ & 7 & 2 & 3 & 3 & 15 \\
\hline Gutiérrez Rodríguez ${ }^{31}, 2009$ & 7 & 2 & 3 & 2 & 14 \\
\hline Dehlin ${ }^{32}, 1985$ & 7 & 2 & 3 & 1 & 13 \\
\hline van Kooten ${ }^{33}, 2017$ & 5 & 2 & 3 & 3 & 13 \\
\hline van de Rijt $^{34}, 2020$ & 7 & 2 & 3 & 2 & 14 \\
\hline
\end{tabular}




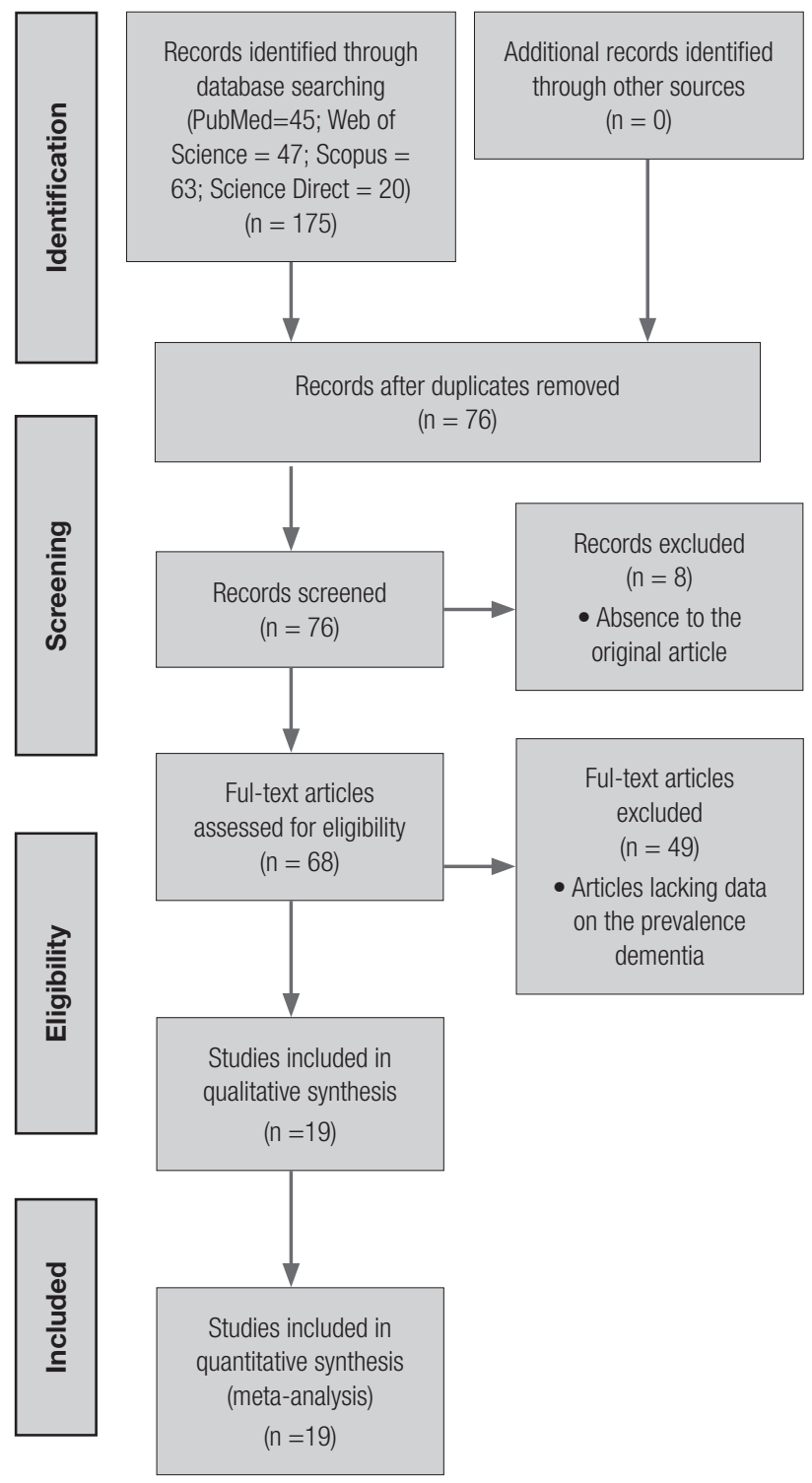

Figure 1. Flowchart showing studies screening, inclusion and exclusion procedures.

\section{Included studies and methods used to screen dementia}

The selected studies were conducted in the following ways: Adolfsson et al. ${ }^{22}$ conducted a demographic study in hospitals, nursing homes, and homes for the aged, with data separation by institution, enabling a specific analysis of the institutionalized elderly group. The Gottfties \& Gottfries (1968) scale was used, which assesses dementia and its severity. In another demographic study, Alvarado-Esquivel et al..$^{29}$ investigated two distinct populations (elderly residents in an institution and patients from elderly centres), allowing separate data visualization from the institutionalized individuals. It used the mini-mental state examination as the first tool for screening cognitive impairment, and those who scored less than 25 went through a specialized medical consultation. The final diagnosis is based on clinical information, on the Diagnostic and Statistical Manual of Mental Disorders (DSM-IV) criteria and laboratory tests, which included blood count, electrolytes, blood glucose, calcium, and TSH. Amuk et al. ${ }^{27}$ studied the prevalence in a single institution, using DSM-IV for the diagnosis of dementia, also applying other cognitive and psychiatric scales to investigate co-morbidities, including MMSE, Hamilton Anxiety Rating Scale, Cornell Scale for Depression in Dementia, Global Deterioration Scale and Multidimensional Observation Scale. Auer et al..$^{23}$ conducted a cross-sectional study which, among other aspects, pointed out the prevalence of dementia in institutionalized elderly based on clinical records, DSM-5 definitions, using the Global Deterioration Scale, MMSE, Brief Cognitive Rating Scale and the Clock for cognitive assessment Drawing Test. Burton et al. ${ }^{21}$, in turn, conducted a cohort-based on admissions to nursing homes, following the individuals for 2 years, with the diagnosis based on specialized medical evaluation, also using the MMSE and based on the DSM III-R criteria. The diagnosis was reviewed by a second team of geriatricians when disagreements occurred. The cross-sectional and socio-demographic study by Dehlin et al. ${ }^{32}$ was comprised entirely of populations in elderly nursing homes (long-term care facilities) or home for the aged, with participants over 70 years old selected, since this age is used in Sweden, the study country, for planning shelter and care in institutions. The Gottfties \& Gottfries scale was used. Donnelly et al. ${ }^{30}$ also carried out a cross-sectional study on the prevalence of dementia in different types of long-term care facilities for the elderly, using the CAPE Survey as a basis for diagnosing dementias. Guo et al. ${ }^{26}$ conducted a study on the prevalence of dementias in long-term care facilities, including nursing and veteran care homes. For diagnostic conclusions, that study relied on structured medical interviews, analysis of medical records and neurological and physical examinations, using the MMSE, Hasegawa Dementia Scale (HDS) and Activities of Daily Living (ADL) as instruments, based on the DSM-III criteria to define dementia. Rodríguez et al. ${ }^{31}$ carried out a cross-sectional epidemiological study in three institutions, demonstrating, among other data, the prevalence of dementia based on the MMSE, also using other questionnaires, such as the Barthel index and the reduced version of the GDS. Helvik et al. ${ }^{13}$, In a cross-sectional study, conducted in two different periods (2004/2005 and 2010/2011), established the prevalence of dementia by assessing the results of 64 institutions. The Clinical Dementia Rating (CDR) was used to diagnose and assess dementia severity. Hutsteiner et al. ${ }^{24}$ conducted a two-year study investigating the prevalence of dementia in nursing homes in rural areas. They collected medical records and performed 
Table 2. Included and analysed articles

\begin{tabular}{|c|c|c|c|c|}
\hline Author, Year & Country & N & Dementia (n) & Prevalence (\%) \\
\hline$X u^{17}, 2017$ & China & 943 & 420 & 45 \\
\hline Helvik $^{13}, 2015$ & Norway & 1163 & 932 & 80 \\
\hline Helvik $^{13}, 2015$ & Norway & 1858 & 538 & 84 \\
\hline Ouanes $^{18}, 2014$ & Tunisia & 77 & 45 & 58 \\
\hline Zwakhalen $^{19}, 2009$ & Netherlands & 179 & 117 & 65 \\
\hline Jakob $^{20}, 2002$ & Germany & 185 & 89 & 48 \\
\hline Burton ${ }^{21}, 2001$ & USA & 2153 & 1063 & 49 \\
\hline Adolfsson ${ }^{22}, 1981$ & Sweden & 780 & 439 & 56 \\
\hline Auer $^{23}, 2018$ & Austria and Czech Republic & 965 & 528 & 54 \\
\hline Hutsteiner ${ }^{24}, 2013$ & Germany & 3,928 & 1,892 & 48 \\
\hline Reuther ${ }^{25}, 2013$ & Germany & 4,777 & 2,531 & 52 \\
\hline Guo $^{26}, 2012$ & China & 264 & 97 & 36 \\
\hline Amuk $^{27}, 2009$ & Turkey & 141 & 88 & 62 \\
\hline Wancata ${ }^{28}, 2004$ & Austria & 249 & 159 & 63 \\
\hline Alvarado-Esquivel29 2004 & Mexico & 155 & 25 & 11 \\
\hline Donnelly $y^{30}, 1989$ & Ireland & 429 & 213 & 49 \\
\hline Gutiérrez Rodríguez $z^{31}, 2009$ & Spain & 215 & 74 & 34 \\
\hline Dehlin ${ }^{32}, 1985$ & Sweden & 200 & 105 & 52 \\
\hline van Kooten ${ }^{33}, 2017$ & Netherlands & 200 & 168 & 84 \\
\hline van de Rijt $^{34}, 2020$ & United Kingdom & 151 & 107 & 70 \\
\hline
\end{tabular}

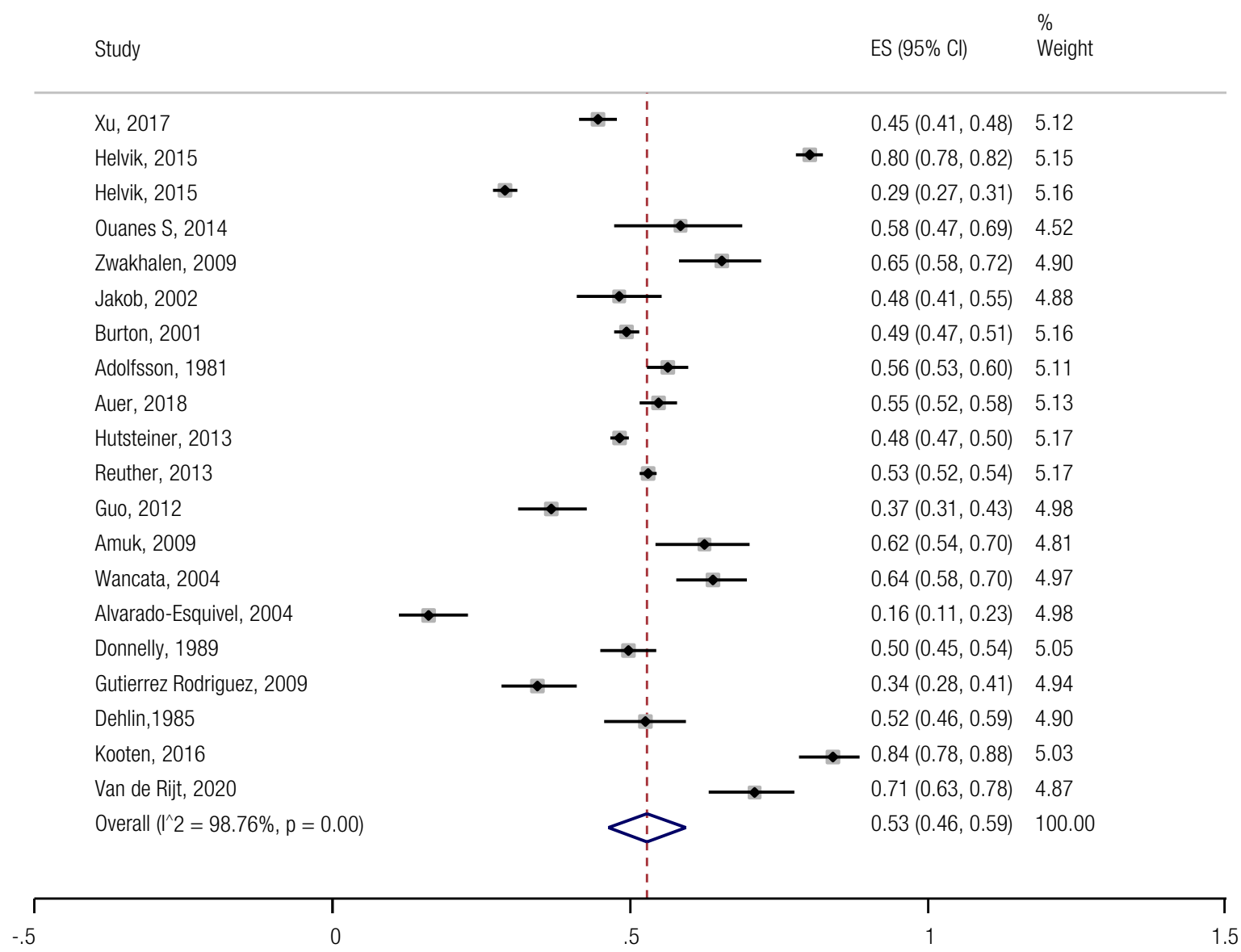

Figure 2. Prevalence of dementia in long-term care institutions. Overall effect $0.53(\mathrm{Cl} 0.46-0.59 ; \mathrm{p}<0.01) . \mathrm{I}^{2}=98.76 \%$. 
structured medical consultations, and based the dementia diagnosis on the DSM-IV definitions and the ICD-10 criteria, using instruments such as the MMSE and the Consortium to Establish a Registry for Alzheimer's disease (CERAD). Jakob et al.20 investigated the prevalence of dementia in nursing homes and institutions for the elderly, in order to compare the data with that of individuals in private homes. The diagnosis of individuals with dementia was performed from the MMSE, clinical analyses and the applied DSM-III-R definitions, in a cross-sectional study. The study performed by Kooten et al. ${ }^{33}$, in turn, investigated the prevalence of pain in institutionalized patients with advanced stage dementia. Despite not having the prevalence of dementia as its main objective, it presents sufficient data to establish this, through expert evaluation and medical records, including dementia subtypes. Ouanes et al. ${ }^{18}$ conducted a crosssectional study for two months in a long-term institution, intending to estimate the prevalence of dementias. The Montreal Cognitive Assessment (MoCA) test was used as a diagnostic strategy. Reuther et al..$^{25}$ carried out a crosssectional, multicentre study, to study the prevalence of malnutrition in patients with dementia. However, in their study, they also present the general prevalence of dementias in institutionalized elderly individuals, using medical records for the diagnosis, which makes it suitable for this review. Wancata et al. ${ }^{28}$ studied the prevalence of non-cognitive symptoms in individuals with dementia. Although this was not the primary objective, this cross-sectional study enabled a detailed analysis of the prevalence of dementias in those individuals institutionalized in nursing homes, based, for diagnostic purposes, on the DSM-III-R. Xu et al. ${ }^{17}$, in a cross-sectional study, demonstrated the prevalence of dementia and its risk factors, utilizing the MMSE and the Clinical Dementia Rating Scale (CDR), applied to estimate impairment severity. The diagnosis was based on the National Institute of Aging and Alzheimer's Association criteria. Zwakhalen et al. ${ }^{19}$ conducted a cross-sectional study on pain in individuals with diseases, allowing for estimates concerning prevalence of dementia in the three institutions where the study was conducted. The dementia diagnosis was obtained based on the DSM-IV. Van de Rijt et al. ${ }^{34}$ used the Clinical Dementia Rating (CDR) for the diagnosis of dementia. Functional assessment was performed using the Barthel index. The aim of the study was to determine the prevalence and associations of orofacial pain and oral health factors in nursing home residents with and without dementia.

\section{Risk of bias}

The visual inspection of FP showed a vertical distribution of the studies with a small asymmetry, indicating a small publication bias (Figure 3).

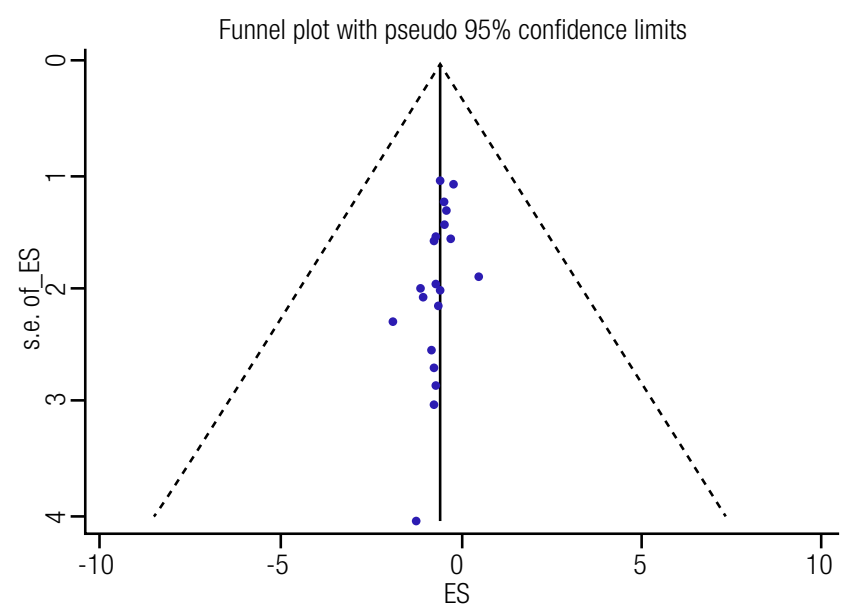

Figure 3. Funnel Plot showing a small risk of bias (small asymmetry) among studies.

\section{DISCUSSION}

This study aimed to systematically review and analyze literature to estimate the prevalence of dementia in LTCls. Our results showed that more than half of the institutionalized older adults are dementia carrier patients (53\%). Comorbidities, physical limitation, and cognitive dysfunction may be the main causes of institutionalization. However, institutionalization increases the risk of cognitive impairment ${ }^{11}$, which could also influence the incidence of dementia. Although the prevalence is high, some studies showed disagreement in their results. Helvik et al..$^{13}$ and van Kooten et al..$^{33}$ conducted their studies in Norway and both showed a prevalence of dementia in LTCls above $80 \%$. It is a surprising data but could be explained accordingly the high lifespan expectation. As the Norway has an elderly population, higher is the risk of dementia. However, Alvarado-Esquivel et al. ${ }^{29}$ showed $11 \%$ of prevalence in an investigation performed in Mexico.

In 2015, from almost 47 million people with dementia, $63 \%$ of them lived in low- or middle-income countries, where health care is relatively limited (e.g., few activities and health professionals to support care) ${ }^{4}$. Estimates of prevalence of dementia in the United Kingdom are $7.1 \%$ of the general population over 65 years ${ }^{37}$, while in the United States of America, Brazil, China and African countries, the prevalence is $8.8 \%, 11.1 \%, 4 \%$, and $4.7 \%$, respectively $4,738,39$. It is an interesting point to be discussed because our metaanalysis showed a prevalence of dementia in LTCls almost five times higher than in general population. A systematic review grouping studies conducted in LTCls and hospitals between 2000 and 2012 demonstrated that the prevalence of dementia is really higher in these locations than in the general community ${ }^{40}$. It reinforces the concerns about the need to elaborate health care strategies for population living 
in LTCls. Early diagnoses and different kind of treatments, especially gathering physical and cognitive stimulation, should be developed in these institutions to prevent dementia and provide a better quality of life for these people.

Functional dependency, physical and mental disabilities, social isolation, low education, low level of physical activity, living alone, depression, smoking, metabolic and chronic diseases are important predictors of institutionalization ${ }^{10,41-43}$. Severe depression is an important factor in institutionalization ${ }^{8}$. Depression is one of the most common psychiatric diseases in the elderly, especially among institutionalized elderly people. It is estimated that 15\% to $52 \%$ of these elderly people in LTCls are affected by mood disorder ${ }^{44}$. Depressive and cognitive disorders coexist in 15\% to $24 \%$ of residents in LTCIs. In these patients, neuropsychiatric symptoms have been associated with dementia severity, with most symptoms occurring in patients presenting severe cognitive decline ${ }^{45}$. Individuals with dementia are at risk of developing depression due to memory loss, which can lead to loss of independence and social isolation ${ }^{46}$. Dementia alone is a predictor of institutionalization, especially due to the caregiver burden ${ }^{8,47}$. Elderly people with severe dementia have a higher tendency of being institutionalized than elderly people with milder dementia. Certain elements of dementia itself, such as severity and functional impairment, predispose to institutionalization ${ }^{48}$. Mild cognitive impairment has less impact on the risk of institutionalization when compared to dementia ${ }^{8}$. In this review, it was not possible to verify whether a higher prevalence of elderly people with more advanced dementia in LTCls ocurrs, since most studies selected by the search strategy did not separate individuals by dementia severity and did not present the cognitive and functionality test values of each patient, so that this data could be obtained. The majority of these risk factors could be changeable, avoiding dependency or dementia, hence preventing early institutionalization. On the other hand, if the institutionalization in LTCls occurs, people deserve a suitable treatment, which should provide a better quality of life. According to the high prevalence of dementia in people living in LTCls, it is clear the necessity to create new strategies to manage older adults living in these institutions. For instance, early differential diagnoses, physical and cognitive massive rehabilitation, simulation of instrumental activities of daily living and social interaction could be provided in every LTCIs. These attitudes towards a normal life could delay physical and mental disabilities of institutionalized older adults.

Some limitations should be highlighted in the current study. Besides the random model of analysis to minimize heterogeneity, different methodologies, especially regarding dementia diagnosis, influence overall results. For example, while Helvik et al. ${ }^{13}$ used the CDR to diagnose dementia, Alvarado-Esquivel et al. ${ }^{29}$ used the MMSE. These methodological differences can directly impact dementia prevalence results. Conducting a prevalence analysis by subgroups of studies with similar methodologies was not feasible from a statistical point of view, since subgroup samples were small, composed of few studies. Furthermore, there were a great number of European studies and few Latin American, African, Asian and Oceania articles. This influences the overall prevalence as the main finding is inflated by results found in Europe. Full studies not found (eight studies) could influence the overall results. Accordingly, we suggest new studies to be conducted in low-income countries since the prevalence of dementia is growing ${ }^{49}$.

\section{CONCLUSION}

Prevalence of dementia is higher in older adults living in LTCls than in those living in general communities. More than half of institutionalized people are demented patients. This data shows a worrying reality that needs to be changed. There is a need for a better understanding of the elements that cause this increase in dementia in LTCFs to direct actions to improve the quality of life and health of institutionalized elderly.

\section{INDIVIDUAL CONTRIBUTIONS}

Daniel Ferreira Fagundes - Wrote the article and analyzed data.

Marcos Túlio Costa - Wrote the article and extracted data from included studies.

Bárbara Bispo da Silva Alves - Extracted data from studies. Maria Madalena Soares Benício - Screened studies.

Lanna Pinheiro Vieira - Screened studies.

Lara S. F. Carneiro - Analysed data and revised the article. Osvaldo José Moreira Nascimento - Revised the article. Renato Sobral Monteiro-Junior - Analysed data and revised the article.

\section{CONFLICT OF INTERESTS}

There is no conflict of interest.

\section{ACKNOWLEDGMENTS}

Authors thank the Conselho Nacional de Desenvolvimento Científico e Tecnológico (CNPq). 


\section{REFERENCES}

1. American Psychiatric Association. DSM-5: Manual Diagnóstico e Estatístico de Transtornos Mentais. 5th ed. Porto Alegre: Artmed; 2014.

2. Custodio N, Wheelock A, Thumala D, Slachersky A. Dementia in Latin America: epidemiological evidence and implications for public policy. Front Aging Neurosci. 2017;9:221.

3. Herrera $E$, Caramelli P, Silveira ASB, Nitrini R. Epidemiologic survey of dementia in a community-dwelling Brazilian population. Alzheimer Dis Assoc Disord. 2002;16(2):103-8.

4. Prince $M$, Guerchet $M$, Prina $M$. The epidemiology and impact of dementia: current state and future trends. Geneva: World Health Organization. 2015 [cited 2021 Jan 23]. Available from: https://www.who.int/mental_health/neurology/dementia/dementia_ thematicbrief_epidemiology.pdf

5. Tinetti ME, McAvay GJ, Murphy TE, Gross (P, Lin H, Allore HG. Contribution of individual diseases to death in older adults with multiple diseases. J Am Geriatr Soc. 2012;60(8)::1448-56.

6. Ballard C, Gauthier S, Corbett A, Brayne C, Aarsland D, Jones E. Alzheimer's disease. Lancet. 2011;377:1019-31.

7. Hebert LE, Weuve J, Scherr PA, Evans DA. Alzheimer disease in the United States (20102050) estimated using the 2010 census. Neurology. 2013;80(19):1778-83.

8. Hajek A, Brettschneider C, Lange C, Posselt T, Wiese B, Steinmann S, et al. Longitudinal predictors of institutionalization in old age. PLoS One. 2015;10(12)

9. Wergeland JN, Selbaek G, Bergh S, Soederhamn U, Kirkevold 0. Predictors for nursing home admission and death among community-dwelling people 70 years and older who receive domiciliary care. Dement Geriatr Cogn Dis Extra. 2015;5(3):320-9.

10. Lini EV, Portella MR, Doring M. Fatores associados à institucionalização de idosos: estudo caso-controle. Rev Bras Geriatr Gerontol. 2016;19(6):1004-14

11. Harmand MGC, Meillon C, Rullier L, Avila-Funes JA, Bergua V, Dartigues JF, et al. Cognitive decline after entering a nursing home: a 22-year follow-up study of institutionalized and noninstitutionalized elderly people. J Am Med Dir Assoc. 2014;15(7):504-8.

12. Hutsteiner $P$, Galler $S$, Mendoza MC, Klunemann HH. Prevalence of dementia in a rural nursing home population in Southern Germany. Eur J Psychiatry. 2013;27(3):174-84.

13. Helvik AS, Engedal K, Benth J, Selbæk G. Prevalence and severity of dementia in nursing home residents. Dement Geriatr Cogn Disord. 2015;40(3-4):166-77.

14. Liberati A, Altman D, Tetzlaff J, Mulrow C, Gotzsche P, loannidis J, et al. The PRISMA statement for reporting systematic reviews and meta-analyses of studies that evaluate healthcare interventions. Ann Intern Med. 2009;151:65-94.

15. Higgins J, Green S. Cochrane Handbook for Systematic Reviews of Interventions. Chichester, UK: Wiley; 2008. v. 8, p. 649.

16. Downs SH, Black N. The feasibility of creating a checklist for the assessment of the methodological quality both of randomised and non-randomised studies of health care interventions. J Epidemiol Community Health. 1998:52(6):377-84.

17. $X u S$, Jin X, Liu C, Jin Y, Xu Y, Chen L, et al. Investigating the prevalence of dementia and its associated risk factors in a chinese nursing home. J Clin Neurol. 2017;13(1):10-4.

18. Ouanes S, Fekih-Romdhane F, Melki W. Prevalence and management of dementia in nursing home residents in Tunisia. Int J Geriatr Psychiatry. 2014;29(8):877-9.

19. Zwakhalen SM, Koopmans RT, Geels PJ, Berger MP, Hamers JP. The prevalence of pain in nursing home residents with dementia measured using an observational pain scale. Eur J Pain. 2009;13(1):89-93.

20. Jakob A, Busse A, Riedel-Heller SG, Pavlicek M, Angermeyer MC. [Prevalence and incidence of dementia among nursing home residents and residents in homes for the aged in comparison to private homes]. Z Gerontol Geriatr. 2002;35(5):474-81.

21. Burton LC, German PS, Gruber-Baldini AL, Hebel JR, Zimmerman S, Magaziner J. Medical care for nursing home residents: differences by dementia status. Epidemiology of dementia in nursing homes research group. J Am Geriatr Soc. 2001;49(2):142-7.

22. Adolfsson R, Gottfries $C_{G}$, Nyström L, Winblad B. Prevalence of dementia disorders in institutionalized Swedish old people. The work load imposed by caring for these patients. Acta Psychiatr Scand. 1981;63(3):225-44.

23. Auer SR, Höfler M, Linsmayer E, Beránková A, Prieschl D, Ratajczak P, et al. Cross-sectional study of prevalence of dementia, behavioural symptoms, mobility, pain and other health parameters in nursing homes in Austria and the Czech Republic: results from the DEMDATA project. BMC Geriatr. 2018;18(1):178.

24. Hutsteiner $\mathrm{P}$, Galler S, Mendoza MC, Klunemann HH. Prevalence of dementia in a rura nursing home population in Southern Germany. Eur J Psychiatry. 2013;27(3):174-84.

25. Reuther S, van Nie N, Meijers J, Halfens R, BartholomeyczikS. [Malnutrition and dementia in the elderly in German nursing homes. Results of a prevalence survey from the years 2008 and 2009]. Z Gerontol Geriatr. 2013;46(3):260-7.

26. Guo MX, Gao L, Zhang GH, Li YM, Xu SS, Wang Z, et al. Prevalence of dementia and mild cognitive impairment in the elderly living in nursing and veteran care homes in Xi'an, China. J Neurol Sci. 2012;312(1-2):39-44.

27. Amuk T, Oguzhanoglu NK, Oguzhanoglu A, Varma GS, Karadag F. Prevalence of dementia, related risk factors and psychiatric comorbidity in nursing home residents. Anadolu Psikiyatri Dergisi. 2009;10(4):301-9.

28. Wancata J, Benda N, Meise U. Non-cognitive symptoms of dementia - Prevalence and consequences a general hospital and nursing home study. Psychiatrische Praxis. 2004;31(7):346-51

29. Alvarado-Esquivel C, Hernández-Alvarado AB, Tapia-Rodríguez RO, Guerrero-Iturbe A, Rodríquez-Corral K, Martínez SE. Prevalence of dementia and Alzheimer's disease in elders of nursing homes and a senior center of Durango City, Mexico. BMC Psychiatry. 2004;4:3.

30. Donnelly CM, Compton SA, Devaney N, Kirk S, McGuigan M. The elderly in long-term care .1. prevalence of dementia and levels of dependency. Int J Geriatr Psychiatry. 1989:4(5):299-304

31. Gutiérrez Rodríguez J, Jiménez Muela F, Alonso Collada A, de Santa María Benedet LS [Prevalence and therapeutic management of dementia in nursing homes in Asturias (Spain)]. Rev Esp Geriatr Gerontol. 2009;44(1):31-3.

32. Dehlin 0, Franzén M. Prevalence of dementia syndromes in persons living in homes for the elderly and in nursing homes in southern Sweden. Scand J Prim Health Care. 1985:3(4):215-22

33. van Kooten J, Smalbrugge M, van der Wouden JC, Stek ML, Hertogh C. Prevalence of pain in nursing home residents: the role of dementia stage and dementia subtypes. J Am Med Dir Assoc. 2017;18(6):522-7.

34. van de Rijt LJ, Feast AR, Vickerstaff V, Lobbezoo F, Sampson EL. Prevalence and associations of orofacial pain and oral health factors in nursing home residents with and without dementia. Age Ageing. 2020;49(3):418-24.

35. Sedgwick P, Marston L. How to read a funnel plot in a meta-analysis. BMJ. 2015;351: h4718.

36. Sterne JA, Egger M. Funnel plots for detecting bias in meta-analysis: guidelines on choice of axis. J Clin Epidemiol. 2001;54(10):1046-55.

37. Prince M, Knapp M, Guerchet M, Mccrone P, Prina M, Comas-Herrera A. Dementia UK: Second Edition - Overview. Alzheimer Society; 2014.

38. Boff MS, Sekyia FS, Bottino CMC. Prevalence of dementia among Brazilian population: systematic review. Rev Med (São Paulo). 2015;94(3):154-61.

39. Zhu Y, Liu H, Lu XL, Zhang B, Weng W, Yang J, et al. Prevalence of dementia in the people's Republic of China from 1985 to 2015: a systematic review and meta-regression analysis. BMC Public Health. 2019:19(1):1-10.

40. Fiest KM, Jetté N, Roberts Jl, Maxwell CJ, Smith EE, Black SE, et al. The prevalence and incidence of dementia: a systematic review and meta-analysis. Can J Neurol Sci. 2016:43(S1):S3-S50

41. Del Duca GF, da Silva SG, Thume E, Santos IS, Hallal PC. Predictive factors for institutionalization of the elderly: a case-control study. Rev Saúde Pública. 2012;46(1):147-53.

42. Neergaard JS, Dragsbæk K, Hansen HB, Henriksen K, Christiansen C, Karsdal MA. Latelife risk factors for all-cause dementia and differential dementia diagnoses in women: a prospective cohort study. Medicine. 2016:95(11):1-7.

43. O'Donnell CA, Browne S, Pierce M, McConnachie A, Deckersn K, Van Boxtel MP, et al. Reducing dementia risk by targeting modifiable risk factors in mid-life: study protocol for the innovative midlife intervention for dementia deterrence (In-MINDD) randomised controlled feasibility trial. Pilot Feasibility Stud. 2015;1(40):1-12.

44. Li ZC, Jeon YH, Low LF, Chenoweth L, O'Connor DW, Beattie E, et al. Validity of the geriatric depression scale and the collateral source version of the geriatric depression scale in nursing homes. Int Psychogeriatr. 2015;27(9):1495-504. 
45. Zuidema SU, de Jonghe JFM, Verhey FRJ, Koopmans R. Predictors of neuropsychiatric symptoms in nursing home patients: influence of gender and dementia severity. Int J Geriatr Psychiatry. 2009;24(10):1079-86.

46. Ray KD, Gotell E. The use of music and music therapy in ameliorating depression symptoms and improving well-being in nursing home residents with dementia. Front Med (Lausanne). 2018;5:287.

47. Eska K, Graessel E, Donath C, Schwarzkopf L, Lauterberg J, Holle R. Predictors of institutionalization of dementia patients in mild and moderate stages: a 4-year prospective analysis. Dement Geriatr Cogn Disord Extra. 2013;3(1):426-45.
48. Bharucha AJ, Pandav R, Shen CY, Dodge HH, Ganguli M. Predictors of nursing facility admission: A 12-year epidemiological study in the United States. J Am Geriatr Soc. 2004;52(3):434-9.

49. World Health Organization (WHO). Dementia: A Public Health Priority. Geneva: WHO; 2012. 